OPEN ACCESS

Edited by:

Janice Swanson

Michigan State University,

United States

Reviewed by:

Agata Malak-Rawlikowska,

Warsaw University of Life Sciences,

Poland

Hayley Randle,

Charles Sturt University, Australia

*Correspondence:

Daniel P. Scheitrum

dpscheitrum@email.arizona.edu

tThese authors have contributed equally to this work

Specialty section:

This article was submitted to Animal Welfare and Policy,

a section of the journal

Frontiers in Animal Science

Received: 13 May 2021 Accepted: 13 September 2021 Published: 12 November 2021

Citation:

Scheitrum DP and Schaefer KA (2021) Farm Animal Enclosure Requirements, Industry Concentration, and Supply Chain Dynamics.

Front. Anim. Sci. 2:709359. doi: 10.3389/fanim.2021.709359

\section{Farm Animal Enclosure Requirements, Industry Concentration, and Supply Chain Dynamics}

\author{
Daniel P. Scheitrum ${ }^{1 * t}$ and K. Aleks Schaefer ${ }^{2 \dagger}$ \\ ${ }^{1}$ Department of Agricultural and Resource Economics, The University of Arizona, Tucson, AZ, United States, ${ }^{2}$ Department of \\ Agricultural Economics, Oklahoma State University, Stillwater, OK, United States
}

In this paper, we draw on microeconomic theory to show that farm animal enclosure regulations can and have lead to increased farm-level concentration in affected industries in the U.S. The desirability of this increased concentration is a function of modern industry structures. Farm animal enclosure requirements can push traditional "short" supply chains like eggs toward vertical integration. However, vertically integrated systems (e.g., broiler chickens and hogs) may benefit from the induced farm-level concentration by increasing bargaining power among contract farmers. In all systems, the increased farm-level concentration induced by enclosure requirements may lead to greater ability to solve future collective action problems like wastewater pollution and antimicrobial resistance.

Keywords: animal welfare, anticompetitive, housing requirements, market power, market concentration

\section{INTRODUCTION}

Concentration in the animal agricultural sector is a growing concern (Watson and Winfree, 2021). Antitrust lawsuits finding and alleging anticompetitive behavior are becoming more frequent (Moss and Alexander, 2020) $)^{1}$. In addition, the COVID-19 pandemic has raised serious concerns about concentration in the food supply as it leads to few points of failure (Moss and Alexander, 2020). Concentrating risk to few points of failure is problematic as any failures are more consequential and disruptive to the market. Additionally, public concern for the well-being of animals being raised for human consumption is also growing in the U.S. and abroad (Clark et al., 2017; Grethe, 2017). Legislation regulating the production practices of animal products is in place in several U.S. states (e.g., California, Colorado, and Oregon) and is pending in many others (e.g., Arizona, Maine, and New York). The main mechanism these legislative efforts employ to improve animal welfare is prohibiting high-density animal housing production practices. Prohibiting this practice necessarily raises the cost of production.

Legislative efforts and public calls for improving animal welfare advocate for industry adoption of practices that are more costly than conventional livestock practices (Grethe, 2017). Voluntary adoption of lower-density housing is only likely to occur if producers believe they can recover the additional costs through higher price premiums from marketing their products as abiding by improved animal welfare practices (Grethe, 2017). The fact that many producers fail to enact these policies voluntarily reveals that producers do not believe they will be rewarded financially

\footnotetext{
${ }^{1}$ For example, broilers, tuna, pork, and beef industries are all currently defending antitrust litigation.
} 
by enhanced animal welfare practices. Achieving widespread adoption of enhanced animal welfare practices requires legislation to compel producers to comply rather than elect voluntarily absent a financial incentive. However, mandating enhanced animal welfare practices will increase costs to the entire industry (Grethe, 2017). These higher costs may result in farms exiting resulting a more concentrated agricultural industry. A more highly concentrated industry raises concerns over stability of the food supply chain and concentration can facilitate anticompetitive behavior. That is, an industry made up of fewer, larger firms is more susceptible to anticompetitive conduct than a perfectly competitive industry with numerous, small firms (U.S. Department of Justice, 2005).

In this paper, we draw on microeconomic theory to show that farm animal enclosure regulations can and have lead to increased farm-level concentration in industries targeted by these regulations. The desirability of this increased concentration is a function of modern industry structures. Farm animal enclosure requirements can push traditional "short" supply chains like eggs toward vertical integration. Eggs have a short supply chain relative to other animal meat products like pork, beef, or broiler chicken as eggs are primarily sold from producer to retailer without a meat processing stage in between. However, vertically integrated systems (e.g., broiler chickens and hogs) may benefit from the induced farm-level concentration by increasing bargaining power among contract farmers. In all systems, the increased farm-level concentration induced by enclosure requirements may lead to greater ability to solve future collective action problems like wastewater pollution and antimicrobial resistance.

Our analysis is structured as follows. Section 2 provides an economic argument for why regulation, as opposed to laissez faire incentives, are needed to solve the animal welfare problem. It then summarizes the current state of farm animal welfare regulation in the U.S. Section 3 explains how animal housing standards lead to increased farm-level concentration. We then test this result empirically based on outcomes in the California and U.S. egg industry following the imposition of minimum cage size requirements in January 2015. Section 4 explains how the increased farm-level concentration induced by enclosure requirements affect the sustainability of national food production in light of modern supply structures. Section 5 concludes with a discussion of actions policymakers can take if they deem the increased concentration induced by farm animal housing requirements unwanted.

\section{STATE OF FARM ANIMAL WELFARE REGULATION}

Consumers are observed to value the treatment of animals that are used in the production of animal products (Clark et al., 2017); however, there is a significant gap between consumers stating they value animal welfare and the actual purchases they make (Paul et al., 2019). The decision on how production animals are raised and treated is made by the producers. Producers will generally adopt animal welfare-enhancing practices that improve the economics of production. For example, hen houses are heated for the comfort of animals which increases egg yield (Wang et al., 2018). However, producers will generally not adopt (and may resist strongly) animal welfare-enhancing practices that increase cost of production (Grethe, 2017).

Consumers have some ability to influence producers through the purchases they make. However, consumers ability to influence the treatment of animals is generally limited to choosing from available options in the marketplace or abstaining entirely from food and clothing products derived from animals. While there are instances where producers will adopt production practices aimed to enhance the welfare of animals in hopes of selling this product for a premium, this is an incomplete approach to resolving animal welfare issues (Carter et al., 2021). Generally, these products make up only a small portion of sales and, therefore, most animals are then raised under conventional practices rather than the enhanced practices (Carter et al., 2021). Further, consumers that care most about animal welfare may be unwilling to accept the price premium because their concern is not just for the animals that produce the products they consume, but for all animals involved in the production of food and clothing. This gap between concern for animal welfare and absence of purchases consistent with that concern is observed in the vote-buy gap (Paul et al., 2019). Consumers will vote for legislation to require certain production practices even though they do not purchase these options when given the option. Furthermore, consumers that abstain from animal products entirely due to their strong concern for animal welfare have no ability to "vote with their wallet" to influence production practices. Consequently, legislation and regulation plays an important role in ensuring the well-being of animals used in the production of food and clothing.

Current animal welfare legislative efforts focus on confinement practices, access to outside areas, humane handling at slaughter, transparency, legal protection of mistreated animals, and ending the practice of concentrated animal feed operations (Animal Agricultural Alliance, 2021). Several states have already passed legislation mandating minimum requirements for animal confinement ${ }^{2}$. Additional states are considering these requirements, and states with existing legislation are considering expanding the scope of animals covered under these protections or increasing the minimum standards.

In the case of layer hens, the initial legislative efforts included language that would require hens be raised in enclosures large enough to allow them to fully extend their limbs. Later, this language was revised to reflect that enclosures could be no smaller than 144 square inches (929 square centimeters), an increase form the conventional practice of 67 square inch enclosures. Continuing efforts to enhance layer hen confinement standards now focus on requiring cage-free production processes with at least 324 square inches of floor space per hen.

It is important to note that many of the first legislative efforts began as citizen-initiated ballot measures (Arizona Secretary of State, 2006; UC Hastings Scholarship Repository, 2008;

${ }^{2} \mathrm{AZ}, \mathrm{CA}, \mathrm{CO}, \mathrm{FL}, \mathrm{KY}, \mathrm{ME}, \mathrm{MA}, \mathrm{MI}, \mathrm{OH}, \mathrm{OR}, \mathrm{RI}$, and WA have all adopted minimum confinement standards of some kind. 

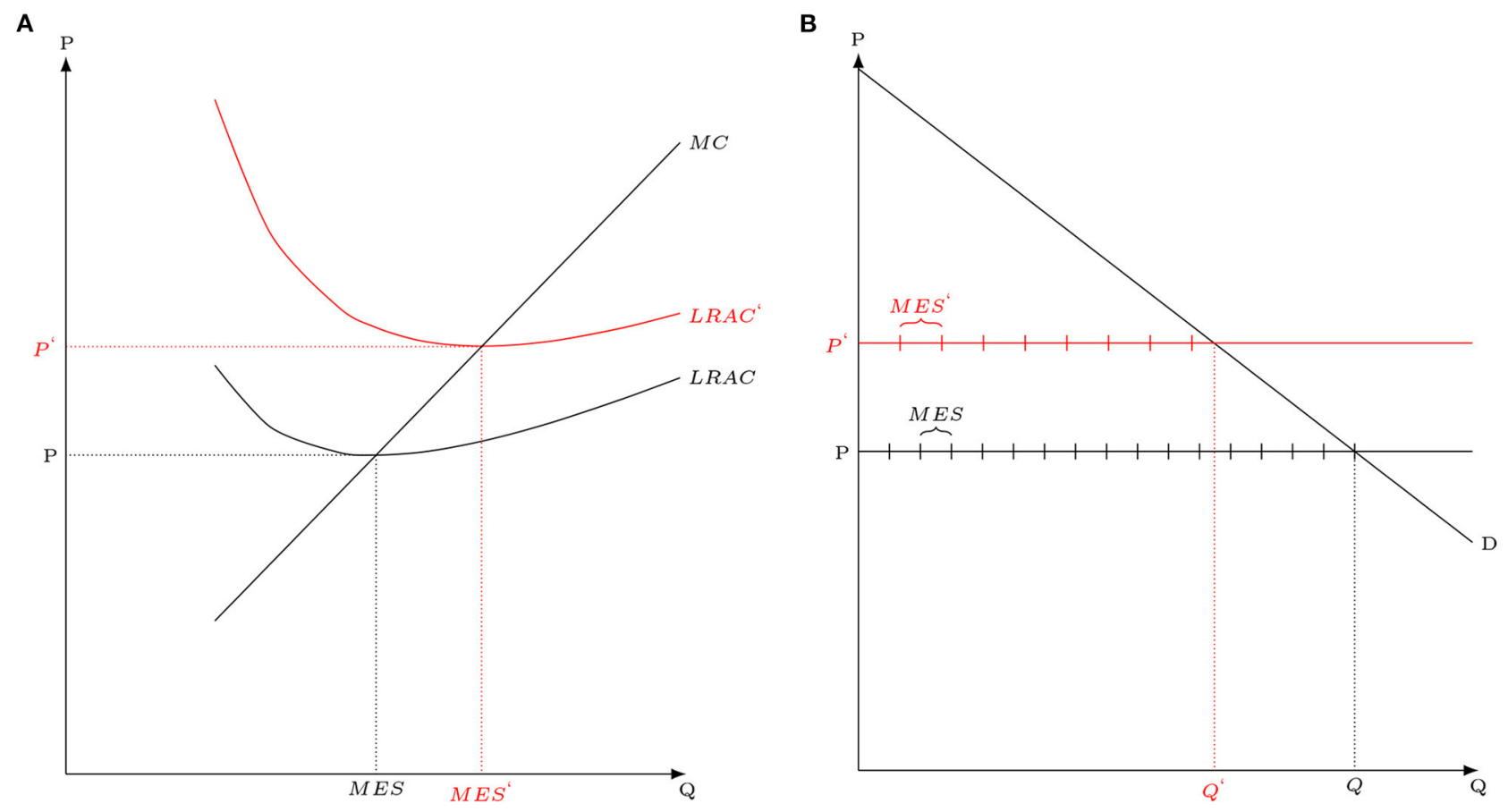

FIGURE 1 | Firm supply and market equilibrium. (A) Firm-level minimum efficient scale. (B) Market supply and demand.

Michigan State University Animal and Legal Historical Center, 2021). These initiatives were introduced by concerned citizens unsatisfied with the actions of their representatives. In the case of California, the ballot proposition was worded in a such a way that only in-state producer would be obligated to abide by the minimum requirements (Sumner et al., 2010). This ballot proposition attracted intense financial support and opposition. Over $\$ 10$ million was raised in support of the proposition, mainly from the Humane Society of the U.S., and approximately $\$ 9$ million was raised in opposition mainly from large egg producers (Ballotpedia, 2021). After the proposition's approval by voters, the CA legislature then had to pass accompanying legislation to ensure the requirements applied to all affected products sold in the state (Carter et al., 2021). Later on, Colorado adopted minimum confinement requirements through the legislature as a way to head off what was seen as a more stringent ballot initiative effort (Brown, 2020).

\section{AW REGULATION AND INDUSTRY CONCENTRATION}

We present a model of an animal food product in Figure 1. Figure 1A presents the long-run average cost curve of a single producer. Economic theory suggests that, in the long-run, in a market with free entry and exit, the market price will resolve where the marginal cost of production equals the long-run average cost, $P=M C=L R A C$. Under this condition, the representative firm (in this case, a farm) operates at the minimum efficient scale (MES) (Davies, 1987). We then consider the introduction of an animal welfare regulation that has the effect of raising the fixed cost of operating the firm ${ }^{3}$. After the imposition of the animal welfare regulation, the firm's minimum efficient scale increases from $M E S$ to $M E S^{\prime}$ and output price increases from $P$ to $P^{\prime}$.

Turning to Figure 1B, we present the market supply and demand for this animal product. Under the assumption that the representative firm operates producing quantity $M E S$ at a price $P$, we indicate on the supply and demand diagram that the equilibrium quantity produced by all firms together is $Q$. The maximum number of firms that can operate in this industry is given by the ratio of MES to industry supply, or $N=$ $\frac{Q}{M E S}$. After the introduction of the animal welfare regulation, our theoretical model indicates the industry will become more concentrated for two reasons. First, the increase in fixed costs prompts each individual firm to increase the quantity produced which leads to larger firms, of which fewer will fit into the existing market. Second, the increase in price, $P$ to $P^{\prime}$, leads to a smaller equilibrium quantity traded in the whole market which accommodates even fewer of the larger firms. In this setting, that means the new equilibrium supports fewer, larger farms.

To confirm our theoretical results, we examine the California hen housing regulations implemented in 2015. Beginning in January 2015, a 2008 ballot proposition (Prop 2) and 2010 assembly bill (AB 1437) went into effect which increased the minimum cage size for hens producing shell eggs from 67 sq.

\footnotetext{
${ }^{3}$ Here, we consider enhanced animal confinement regulations, but a variety of animal welfare regulations could have the same impact to the economics of producer operations.
} 
inches to 117 sq. inches (Carter et al., 2021). To determine the degree of concentration in the egg industry and examine the impacts of the regulation, we compute the four-firm concentration ration (CR4) for California and the rest of the U.S. The CR4 measures the share of the market served by the four largest firms. We obtain data from WATT Poultry on the largest 68 egg producers in the U.S. from 2014 to 2019. From this information, we are able to identify the four largest egg producers in California, and the four largest in the rest of the U.S. We then plot the CR4 in California and CR4 in the rest of the U.S. from 2014 to 2019. As shown in Figure 2, prior to the policy taking effect, the concentration ratio in California is similar to rest of the U.S. at 34 and $24 \%$, respectively. After the policy is implemented, the CR4 in California doubles to $68 \%$, while the concentration ratio is relatively unchanged in the rest of the U.S. This result continues through the end of our data.

\section{SUPPLY CHAINS AND INDUSTRY CONCENTRATION}

Of course, for the four industries most affected by farm animal enclosure requirements (eggs, dairy, broiler chicken, and hogs), the shift in concentration induced by farm animal enclosure requirements is not an abrupt transition away from the "Jeffersonian Ideal" of a countryside speckled with small farms. Rather, it is an acceleration of a steady march that has taken place over the last two decades.

\subsection{One Size Does Not Fit All in Livestock Supply Chain Structure}

Modern concentration patterns lie on a continuum within the livestock sector. The egg industry, on one side of the continuum, has a relatively low level of concentration-the top four companies accounted for approximately $28.5 \%$ of industry revenues in 2020 (IBISWorld, 2020). On the other side of the continuum, the four biggest pork integrators (Smithfield, JBS, Tyson, Cargill) account for 66 percent of America's hog slaughter (Willingham and Green, 2019). Similarly, the top three broiler processors (Tyson, Pilgrim's Pride, and Sanderson) account for approximately half of nation's chicken production (Alonzo, 2016). In the middle of the continuum, the top four dairy cooperatives produce approximately $40 \%$ of dairy in the U.S. (Shields, 2010). We note that the beef industry is even more concentrated. The top four beef packers process $85 \%$ of all beef (Hirtzer, 2020). However, farm animal enclosure requirements (the subject of this article) are not relevant for beef cattle.

Current levels of concentration across different livestock industries are primarily a function of supply chain structures and economies of scale. Figure 3 presents a schematic representation of the supply chains for the eggs, dairy, broiler chickens, and hogs-the four industries most targeted by farm animal housing requirements. The eggs industry has a relatively "short" supply chain (Malone et al., 2020). The majority of egg producers $(\approx 70 \%)$ sell directly to food retail locations almost exclusively in the form of table eggs (Malone et al., 2020). Other egg producers $(\approx 30 \%)$ sell liquid eggs for use in the food service



FIGURE 2 | Egg industry concentration in CA vs. Rest of U.S. Source: Data on number of layer hens in inventory for four largest firms from WATT Poultry. Data on number of layer hens in inventory for CA and rest of U.S. from USDA NASS.

industry or dry eggs for use in processed foods (Malone et al., 2020). Differential regulatory treatment under the Food and Drug Administration Egg Safety Rules (21 CFR Part 118) impede liquid and dry egg producers from selling into the retail market (Malone et al., 2020).

The dairy supply chain is "longer" than the eggs supply chain in the sense that individual dairy farms send their raw milk to an intermediary dairy processor, which is typically cooperatively owned by the individual farms (Smart Sense, 2018). The dairy processor then converts the raw milk into pasteurized fluid milk or other dairy products (e.g., cheese, yogurt, and whey). The cooperative processor then markets the various outputs to retail stores or (in bulk) to food service and food manufacturers (Smart Sense, 2018).

In the U.S., the supply chains for broiler chickens and hogs work very differently from dairy and eggs. Broiler chicken and hog supply chains are "vertically integrated"-large processing companies are responsible for almost all stages of production from research and development into the breeding stock and genetic base through to the processing and marketing of finished meat and other animal products (Ward, 1997). Under this model, processors contract with independent farmers who raise-but do not own-the animals, which are then sent to the processing plants once they are mature. Today, there are about 25,000 contract farms in the broiler chicken industry and 60,000 contract farms in the swine industry (National Chicken Council, 2019; Freese, 2020).

Under the vertically integrated business model, the pork and hogs industries have seen astonishing productivity growth. For example, the feed conversion ratio for broiler chicken decreased from about 3.5 pounds of feed per pound of meat to about $2.7-\mathrm{a}$ 23\% increase in efficiency-between 1960 and 2016 (Mekonnen et al., 2019). Over the same period, the feed conversion ratio for hogs went from 6 pounds of feed per pound of meat to about 4 pounds of feed per pound of meat-a 33\% increase in efficiency (Mekonnen et al., 2019). However, vertically integrated supply 


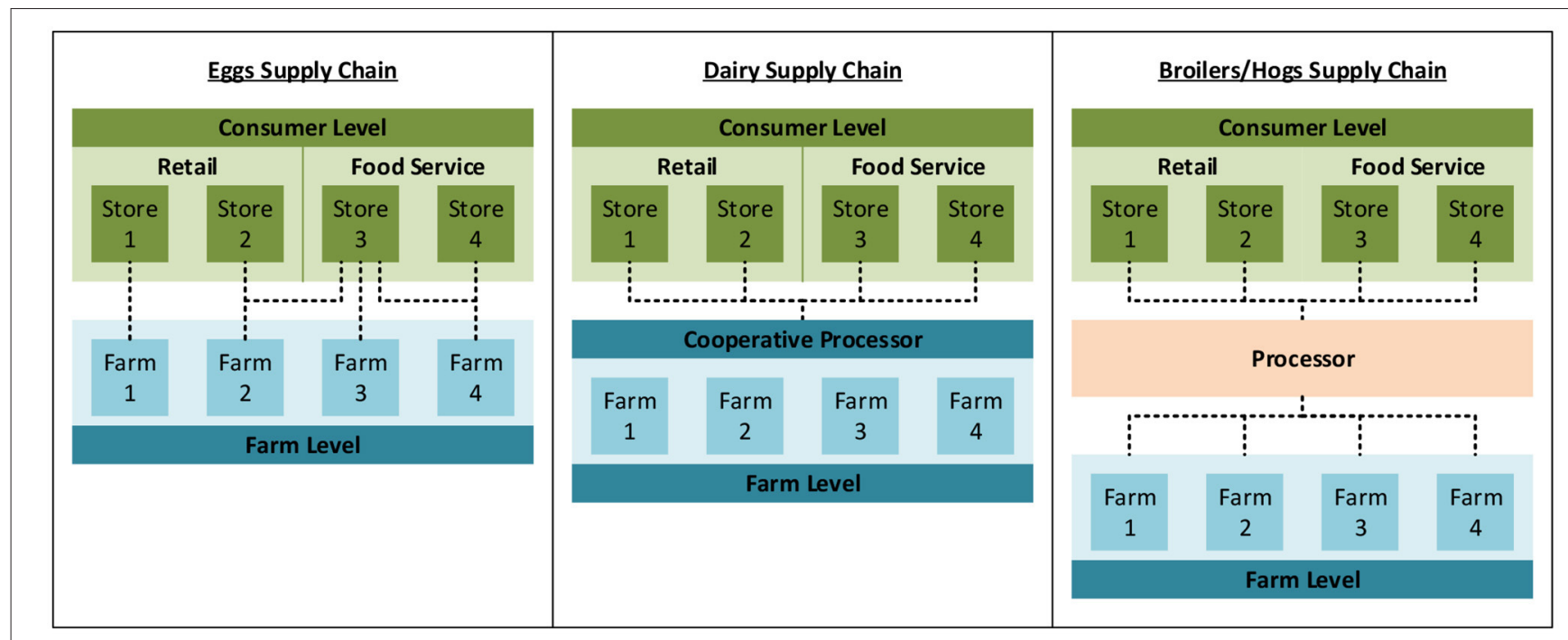

FIGURE 3 | Schematic representation of livestock supply chains.

chains have also been criticized for exploitation of contract farmers (Leonard, 2014).

\subsection{Pros and Cons of Increased Farm-Level Concentration}

Given the differences in supply structure among the eggs, dairy, broiler chickens, and hogs industries, the impacts of increased farm-level concentration induced by animal housing requirements has very different impacts. Here we investigate "short" supply chains (those without an intermediate processing step), as well as "long" supply chains (those that include one or more intermediate processing step between producer and retailer).

\subsection{1. "Short" Supply Chains}

For "short" supply chain industries like eggs and dairy, where existing concentration levels are relatively low, the increased concentration can lead to supply chains less resilient to shocks, push the industry in a direction more conducive to oligopsonistic market power, and lead the industry in a direction more conducive to the collusion currently at issue in many agriculture anti-trust cases.

At the onset of the COVID-19 pandemic, the relationship between industry concentration and resilience was clear and obvious for the highly concentrated beef and hog industries (Moss and Alexander, 2020). Employees of food manufacturing facilities were deemed "essential workers" and were required to resume in-person responsibilities amidst closure of other businesses and shelter-at-home requirements. In early April 2020, global news began to highlight that beef and pork processing facilities served as a hotbed for infection (Lussenhop, 2020). Workers in these industries faced the decision to go to work and risk infection, or stay at home and risk unemployment. For many, of course, the latter option meant food and housing insecurity and increased uncertainties about immigration status
(Malone et al., 2021). Unsurprisingly, the public health impacts were severe. Recent research suggests that, in total, meatpacking plants contributed approximately 331,000 county-level COVID19 infections with a public health cost of more than $\$ 3.5$ billion between March and November 2020 (Saitone et al., 2021). The poor resilience of beef and pork supply chains due to high concentration also exacted a large economic toll. In April 2020, closure of large pork packing plants due to disease outbreaks led to a drop in national processing throughput of about $40 \%$ (Lusk, 2020).

There were issues in other food supply chains due to COVID19 as well. Retail prices for eggs, for example, increased by approximately $141 \%$ at the onset of the pandemic (Malone et al., 2020). These price spikes lead to price gouging suits in several states (Malone et al., 2020). However, because egg processing was less concentrated, there were no widespread declines in processing capacity. Egg supply issues were mostly resolved within the first 2 months of the pandemic (Malone et al., 2020).

\subsubsection{Vertically Integrated Supply Chains}

Perhaps counterintuitively, in vertically integrated systems, the increased concentration induced by farm-level animal enclosure restrictions can serve as a pro-competitive mechanism. In these systems, the lion's share of industry profits flow to the large processors (Smithfield, JBS, Tyson, and Cargill for pork and Tyson's, Pilgrim's Pride, and Sanderson for broilers) who extract both seller-power rents from consumers and buyer-power rents from farmers (Saitone et al., 2015). As farms become larger as a result of enclosure requirements, they undoubtedly increase their bargaining power with these large intermediaries, thereby leading to fairer terms for themselves and-over the mediumto long-term-for other farmers. In other words, in a vertically integrated system, farm animal housing regulations can serve to counteract processor buyer power (monopsony power) and increase profitability for contract farmers. 


\subsubsection{Industry Concentration and Collective Action}

In all types of supply chains, increased concentration may assist in the future-proofing of food supply chains by helping to solve other critical collective action problems. Several of the issues most crucial to the ongoing sustainability of modern agriculture, such as wastewater pollution and antimicrobial resistance, are characterized in the economics literature as collective action problems. These problems arise when society would be better off if a group of individuals worked together to solve a problem. However, the individuals in the group are disincentivized from taking pro-active actions on their own. In the agricultural context, firms are not incentivized to unilaterally limit the use of antimicrobials or invest in best management practices for wastewater because such actions increases costs without increasing revenues. Further, the benefits to the firm (and society at large) of a single firm taking such pro-active steps are miniscule if the industry at large does not follow suit.

Increased industry concentration helps solve collective action problems in two ways. First, because firms are larger, they are more able to unilaterally internalize the consequences of their own actions. For example, if a firm is able to effectively limit the rate at which resistance to its antimicrobials spreads by reducing their usage (as opposed to having no control over AMR because the firm's many competitors are over-using such technologies, too), the firm will be more willing to limit usage of antimicrobials. This will increase the firm's costs in the short run but preserve the efficacy of the treatments over the longer run. As a second, and perhaps less esoteric, point, the fewer the number of firms in an industry, the fewer actors needed to coordinate to effectively solve a collective action problem. Thus, by increasing concentration the policymaker also facilitates industry engagement. We note that this is related to the logic offered above that fewer firms also means more opportunity and ability to engage in collusive activity.

\section{CONCLUSION}

This paper employs microeconomic theory to show how regulations mandating farm animal enclosure requirements can and have lead to increased farm-level concentration. The consequences of this increased concentration can be both negative and positive. These enclosure requirements may shift traditional "short" supply chains like eggs toward vertical integration. However, increased farm-level industry

\section{REFERENCES}

Alonzo, A. (2016). Top 5 Broiler Producers Dominate Us Production. Available online at: https://www.wattagnet.com/articles/26925-top-5-broiler-producersdominate-us-production

Animal Agricultural Alliance (2021). Issues: Legistlation. Available online at: https://animalagalliance.org/issues/legislation/?fbclid=IwAR08JAohHlmE3zOp GobAOyVBE_9OlB4jEtFAwDXau5L2iUPvjSWh64FLhEs

Arizona Secretary of State (2006). 2006 Ballot Proposition Guide. Available online at: https://web.archive.org/web/20060928035155/http://www.azsos.gov/ election/2006/Info/PubPamphlet/Sun_Sounds/english/Prop204.htm concentration may benefit producers in vertically integrated systems (e.g., broiler chickens and hogs) by increasing bargaining power among contract farmers relative to processors. The resulting increased farm-level concentration may lead to greater ability to solve future collective action problems like wastewater pollution and antimicrobial resistance.

Policymakers who deem the increased concentration induced by farm animal housing requirements unwanted are not left without recourse. There are solutions to solve the welfareconcentration trade-off if the policymaker decides the costs of increased concentration outweigh the benefits. Removing the fixed-cost barriers to adoption of regulation-compliant housing systems returns to the industry to previous levels of concentration. Of course, this may be easier said than done. While governments may be tempted to couple enhanced animal welfare regulations with financial support programs to prevent farm exit and the resulting market concentration, such programs likely violate international trade law. Introducing agricultural support programs to ease the transition to enhanced animal welfare practices would likely by challenged by U.S. trade partners for violating World Trade Organization (WTO) prohibitions on trade-distorting policies.

\section{DATA AVAILABILITY STATEMENT}

The data analyzed in this study is subject to the following licenses/restrictions: The empirical analysis conducted relies on proprietary data, Top US egg producers 2014-2019, available for purchase at Watt Global Media. Their policy states, once purchased, data files are for use by the purchaser only and sharing is strictly prohibited without the prior written consent of WATT Global Media. Requests to access these datasets should be directed to https://www.wattglobalproducts.com/collections/ wattagnet-products.

\section{AUTHOR CONTRIBUTIONS}

All authors listed have made a substantial, direct and intellectual contribution to the work, and approved it for publication.

\section{ACKNOWLEDGMENTS}

The authors would like to thank Professor Sergio Puig, Austin Frerick, and the participants of the Big Ag and Antitrust Conference for their valuable feedback.
Ballotpedia (2021). California Proposition 2, Standards for Confining Farm Animals 2008. Available online at: https://ballotpedia.org/California_Proposition_2, Standards_for_Confining_Farm_Animals_(2008)

Brown, J. (2020). All Colorado Eggs Must be Cage-Free by 2025 Under Law Passed to Head Off Stricter Ballot Measure. The Colorado Sun. Available online at: https://coloradosun.com/2020/07/01/colorado-cage-freeegg-law/

Carter, C. A., Schaefer, K. A., and Scheitrum, D. (2021). Piecemeal farm regulation and the US Commerce clause. Am. J. Agric. Econ. 103, 1141-1163. doi: 10.1111/ajae. 12104 
Clark, B., Stewart, G. B., Panzone, L. A., Kyriazakis, I., and Frewer, L. J. (2017). Citizens, consumers and farm animal welfare: a meta-analysis of willingnessto-pay studies. Food Policy 68, 112-127. doi: 10.1016/j.foodpol.2017.01.006

Davies, R. B. (1987). Hypothesis testing when a nuisance parameter is present only under the alternative. Biometrika 74, 33-43.

Freese, B. (2020). What It Takes to Add Contract Hog Finishing to Your Farm. Successful Farming. Des Moines, IA.

Grethe, H. (2017). The economics of farm animal welfare. Annu. Rev. Resour. Econ. 9, 75-94. doi: 10.1146/annurev-resource-100516-053419

Hirtzer, M. (2020). Senators Ask FTC to Probe Meat-Industry Consolidation. Available online at: https://www.bloomberg.com/news/articles/2020-04-29/ senators-ask-trade-agency-to-probe-meat-industry-consolidation

IBISWorld (2020). Chicken Egg Production Industry in the US. Available online at: https://www.ibisworld.com/united-states/market-research-reports/chickenegg-production-industry/\#: :text=Competitive\%20Landscape-, Market $\% 20$ Share $\% 20$ Concentration, $28.5 \% 25 \% 20$ of $\% 20$ revenue $\% 20$ in $\% 202020$

Leonard, C. (2014). The Meat Racket: The Secret Takeover of America's Food Business. New York, NY: Simon and Schuster.

Lusk, J. (2020). The Scale of the Problem. Available online at: http://jaysonlusk.com/ blog/2020/4/29/the-scale- of-the- problem

Lussenhop, J. (2020). Coronavirus at Smithfield Pork Plant: The Untold Story of America's Biggest Outbreak. BBC News. London.

Malone, T., Schaefer, K. A., and Lusk, J. (2020). Unscrambling Covid-19 Food Supply Chains. Available at SSRN 3672018.

Malone, T., Schaefer, K. A., and Wu, F. (2021). The razor's edge of "essential" labor in food and agriculture. Appl. Econ. Perspect. Policy 43, 368-381. doi: 10.1002/aepp.13070

Mekonnen, M. M., Neale, C. M. U., Ray, C., Erickson, G. E., and Hoekstra, A. Y. (2019). Water productivity in meat and milk production in the US from 1960 to 2016. Environ. Int. 132:105084. doi: 10.1016/j.envint.2019. 105084

Michigan State University Animal and Legal Historical Center (2021). West's Florida Statutes Annotated. Florida Constitution-1968 Revision. Available online at: https://www.animallaw.info/statute/fl-cruel-confinement-\%C2 $\% A 7-21$-limiting-cruel-and-inhumane-confinement-pigs-during-pregnancy

Moss, D. L. and Alexander, L. (2020). When Covid-19 is the Symptom and Not the Disease: Consolidation, Competition, and Breakdowns in Food Supply Chains. American Antitrust Institute. Available online at: https:// www.antitrustinstitute.org/work-product/when- covid-19-is-the-symptomand-not-the-disease-consolidation-competition-and-breakdowns-in-foodsupply-chains/

National Chicken Council (2019). Broiler Chicken Industry Key Facts 2019. Available online at: https://www.nationalchickencouncil.org/about-theindustry/statistics/broiler-chicken-industry-key-facts/\#: :text=Broiler \%20Chicken\%20Industry\%20Key\%20Facts\%202019,-Approximately\%2030 $\% 20$ federally\&text=About $\% 2025 \% 2$ C000\%20family\%20farmers $\% 20$ have, raised $\% 20$ on\%20 company $\% 2$ Downed $\% 20$ farms

Paul, A. S., Lusk, J. L., Norwood, F. B., and Tonsor, G. T. (2019). An experiment on the vote-buy gap with application to cage-free eggs. J. Behav. Exp. Econ. 79, 102-109. doi: 10.1016/j.socec.2019.02.005

Saitone, T., Schaefer, K. A., and Scheitrum, D. P. (2021). Covid-19 morbidity and mortality in US meatpacking counties. Food Policy 101:102072. doi: 10.1016/j.foodpol.2021.102072
Saitone, T. L., Sexton, R. J., and Sumner, D. A. (2015). What happens when food marketers require restrictive farming practices? Am. J. Agric. Econ. 97, 1021-1043. doi: 10.1093/ajae/aav021

Shields, D. A. (2010). Consolidation and Concentration in the US Dairy Industry.

Smart Sense (2018). From Farm to Fork: The Dairy Supply Chain. Washington, DC. Available online at: https://blog.smartsense.co/farm-to-fork-dairy-supplychain\#: :text=The\%20dairy\%20supply\%20chain $\% 20$ starts, at $\% 20$ below $\% 2040$ $\% \mathrm{C} 2 \% \mathrm{~B} 0 \mathrm{~F}$

Sumner, D. A., Matthews, W. A., Mench, J. A., and Rosen-Molina, J. T. (2010). The economics of regulations on hen housing in California. J. Agric. Appl. Econ. 42, 429-438. doi: 10.1017/S1074070800003618

U.S. Department of Justice (2005). Price fixing, bid rigging, and market allocation schemes: what they are and what to look for. Antitrust Primer 28:2005. Available online at: https://www.justice.gov/atr/file/810261/download

UC Hastings Scholarship Repository (2008). Propositions. Available online at: https://repository.uchastings.edu/ca_ballot_props/1282/

Wang, Y., Zheng, W., Shi, H., and Li, B. (2018). Optimising the design of confined laying hen house insulation requirements in cold climates without using supplementary heat. Biosyst. Eng. 174, 282-294. doi: 10.1016/j.biosystemseng.2018.07.011

Ward, C. E. (1997). Vertical Integration Comparison: Beef, Pork, and Poultry. Technical report. Oklahoma Cooperative Extension Service.

Watson, P., and Winfree, J. (2021). Should we use antitrust policies on big agriculture? Appl. Econ. Perspect. Policy. doi: 10.1002/aepp.13173. [Epub ahead of print].

Willingham, Z. and Green, A. (2019). A Fair Deal for Farmers. Center for American Progress. Available online at: https://www.americanprogress. org/issues/economy/reports/2019/05/07/469385/fair-deal-farmers/\#: :text= Pork\%20production\%20is\%20centered\%20in,sales\%20in\%20the\%20United \%20States.\&text=Since $\% 201985 \% 2$ C $\% 20$ the $\% 20$ hog $\% 20$ industry, to $\% 2065$ $\% 20$ percent $\% 20$ in $\% 202008$

Conflict of Interest: The authors declare that the research was conducted in the absence of any commercial or financial relationships that could be construed as a potential conflict of interest.

The handling editor declared a shared affiliation with one of the authors KS at the time of review.

Publisher's Note: All claims expressed in this article are solely those of the authors and do not necessarily represent those of their affiliated organizations, or those of the publisher, the editors and the reviewers. Any product that may be evaluated in this article, or claim that may be made by its manufacturer, is not guaranteed or endorsed by the publisher.

Copyright (๑) 2021 Scheitrum and Schaefer. This is an open-access article distributed under the terms of the Creative Commons Attribution License (CC BY). The use, distribution or reproduction in other forums is permitted, provided the original author(s) and the copyright owner(s) are credited and that the original publication in this journal is cited, in accordance with accepted academic practice. No use, distribution or reproduction is permitted which does not comply with these terms. 